\begin{tabular}{|c|c|c|}
\hline $1+4$ & $\begin{array}{l}\text { European Association for the } \\
\text { Development of Renewable Energies, Environment } \\
\text { and Power Quality (EA4EPQ) }\end{array}$ & $\begin{array}{l}\text { International Conference on Renewable Energies and Power Quality } \\
\text { (ICREPQ'12) } \\
\text { Santiago de Compostela (Spain), 28th to 30th March, } 2012\end{array}$ \\
\hline
\end{tabular}

\title{
FEM Thermomechanical Simulation of Low Power LED Lamp for Energy Efficient Light Sources
}

\author{
P. Kulha ${ }^{1}$, J. Jakovenko ${ }^{1}$, J. Formanek ${ }^{1}$ \\ ${ }^{1}$ Department of microelectronics \\ Faculty of Electrical Engineering \\ Czech Technical University in Prague \\ Technicka 2, 16627 Prague (Czech Republic) \\ Phone number: +420 224352 266, e-mail: kulhap@fel.cvut.cz
}

\begin{abstract}
Modeling and simulation of thermal distribution, heat transfer, and mechanical stress are virtually essential for any design of structures and devices in electronic industry. The modern simulation tools make the design easier and enable optimization of many different parameters before fabrication of new structure. This paper presents simulation validation of 3D model of solid state lighting LED bulb for energy efficient and durable light sources. The modeling of structures was performed by CoventorWare tools utilizing finite the element method (FEM). The calculated thermal distribution has been validated with thermal measurement on a commercial LED lamp. Materials parametric study has been carried out to discover problematic parts for heat transfer from power LEDs to ambient.
\end{abstract}

\section{Key words}

FEM, thermal simulation, mechanical simulation, solid state lighting, LED

\section{Introduction}

The usage of LED (Light Emitting Diode) light bulbs (lamps) in household (and also industrial and automotive) lighting systems has been increasing rapidly in the past few years. It is a rapidly-emerging technology to replace classic incandescent light bulbs and also to the compact fluorescent lamps due to their discrete spectral characteristic and utilizing of toxic metals (e.g. mercury). First commercial prototypes of $600 \mathrm{~lm}$ LED lamps were introduced recently to replace incandescent bulbs. The environmentally friendly technology, without any toxic materials, is starting to replace classic lighting even faster than expected [1]. In today's high power LED applications thermal management issues must be taken into account $[2,3]$ to ensure light maintenance and quality, and life time of LED lamps.

\section{Numerical Solution Using FEM}

In FEM, a distributed physical system to be analyzed is divided into a number (often large) of discrete elements. The complete system may be complex and irregularly shaped, but the individual elements are easy to analyze. The examined region is covered by a discretization net compiled from a finite number of generally $3 \mathrm{D}$ elements. In contrast to the Finite Difference Method, the discrete element can have any shape from the simplest (triangles) to the very complex (tetrahedrons) in the case of FEM. Tetrahedrons are universal and flexible enough for contouring any shape or boundary. Generally, the elements may be 1-D, 2-D (triangular or quadrilateral), or 3-D (tetrahedral, hexahedral, etc.) and may be linear or of higher order (Fig. 1).

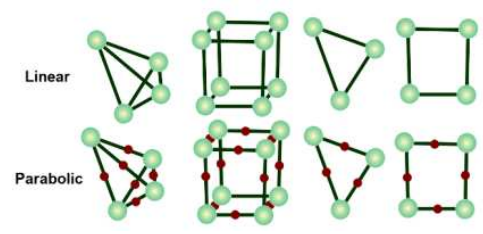

Fig. 1. FEM element configurations

In every discrete element, it is necessary to fit real distribution of the examined quantity by a suitable function. This function must take real values in all significant points of the element. In the case of aforementioned tetrahedron, it is possible to choose the function as a linear combination of values of the examined quantity in its vertices (linear approximation), or in other significant nodes such as edge or face midnodes (quadratic or higher order approximation).

It leads to a very complex system of algebra equations. Coefficients of this system can be both constant (in a linear environment) and dependent on solution size (in a non-linear environment). In the first case, a discrete model is computed in a single step, in the second, is necessary to use appropriate iteration process. 


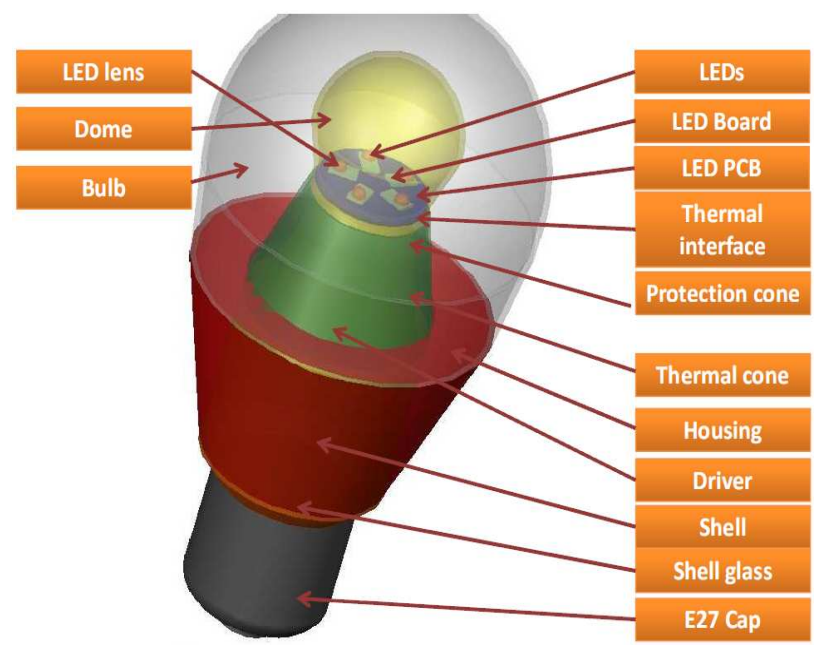

Fig. 2. Simplified CoventorWare 3D model of LED lamp with part description

At present time, this methodology is used in most cases for computing mechanical and thermomechanical effects in structures.

\section{LED Lamp 3D Model}

The software package CoventorWare has been used for design of mechanical and thermal characteristics of the structure. The tools enable design, modeling and successive modification of designed structures.

The program enables: drawing of 2D layout and its editing, simulation of production process, generation of 3D model from 2D layout, generation of network by the method of finite elements, solution of mechanical, electrostatic, thermal, piezoresistive, induction, optical, and further simulations.

The model represents a retrofit LED lamp including six LEDs mounted on PCB board. On each of the LEDs a silicon lens is placed in order to get a wide angle light beam. A polycarbonate dome containing phosphors has been installed for light conversion. High power LEDs are usually based on $\mathrm{GaN}$ solid state semiconductors. The model contains also an electronic driver board, a thermal cone and housing (heat sink). Other details as E27 cap, shell, potting material, reflective cover, driver support and TIM between LED board and thermal cone are also included in the model (as is depicted in Fig. 1).

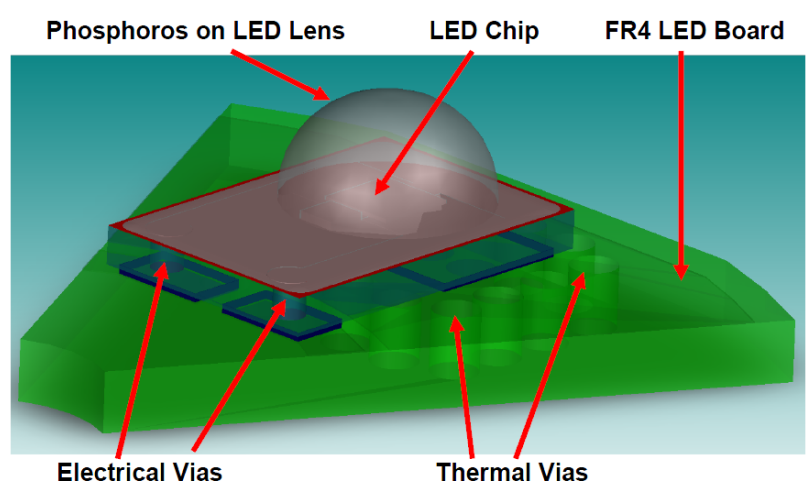

Fig. 4. Detail of LED board section with detail of thermal vias and electrical vias on LED

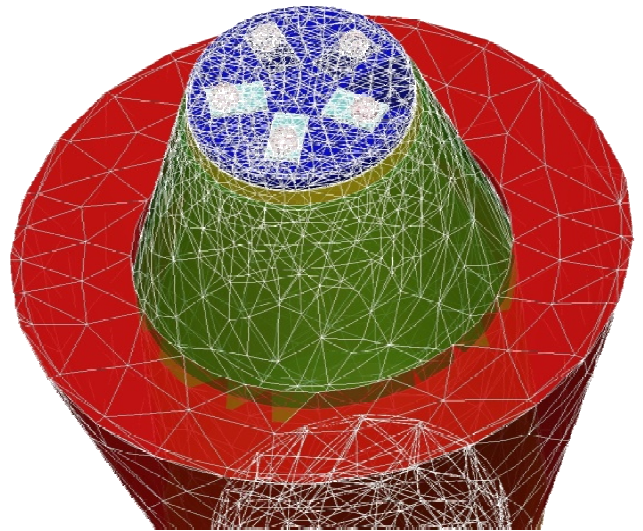

Fig. 3. Detail of discretizing tetrahedron mesh on led board, thermal cone and housing

For successful and precise simulation, it is necessary to input all material constants used for LED bulb construction correctly.

Table I. - Thermal properties of the material used

\begin{tabular}{|c|c|c|c|}
\hline Part & Material & $\begin{array}{c}\text { Thermal } \\
\text { Conductivity } \\
\lambda(\mathrm{W} / \mathrm{mK})\end{array}$ & $\begin{array}{c}\text { Specific } \\
\text { heat } \\
\text { Cp }(\mathbf{J} / \mathbf{k g K})\end{array}$ \\
\hline Bulb & Glass (Forced) & 1.1 & 840 \\
\hline Dome & Polycarbonate & 0.2 & 2000 \\
\hline LED Board & FR4 & 40.0 & 1085 \\
\hline $\begin{array}{l}\text { Thermal } \\
\text { Interface }\end{array}$ & $\begin{array}{l}\text { Silicone base gap } \\
\text { filler }\end{array}$ & 2 & 1460 \\
\hline $\begin{array}{c}\text { Thermal } \\
\text { cone }\end{array}$ & Aluminium & 100 & 880 \\
\hline Housing & Polyamide6 & 4 & 1130 \\
\hline $\begin{array}{l}\text { Sillicone } \\
\text { glue }\end{array}$ & Silicone glue & 0.22 & 1460 \\
\hline $\begin{array}{l}\text { Potting } \\
\text { material }\end{array}$ & Silicone rubber & 0.22 & 1460 \\
\hline $\begin{array}{c}\text { Driver } \\
\text { support }\end{array}$ & $\begin{array}{l}\text { PBT(Glass } \\
\text { reinforced) }\end{array}$ & 0.27 & 1700 \\
\hline E27 Cap & Brass Ni & 122 & 380 \\
\hline \multirow{4}{*}{ LED } & $\mathrm{GaN}$ & 130 & 490 \\
\hline & Silicone & 0.22 & 1460 \\
\hline & Copper & 400 & 385 \\
\hline & Silicon & 130 & 700 \\
\hline
\end{tabular}

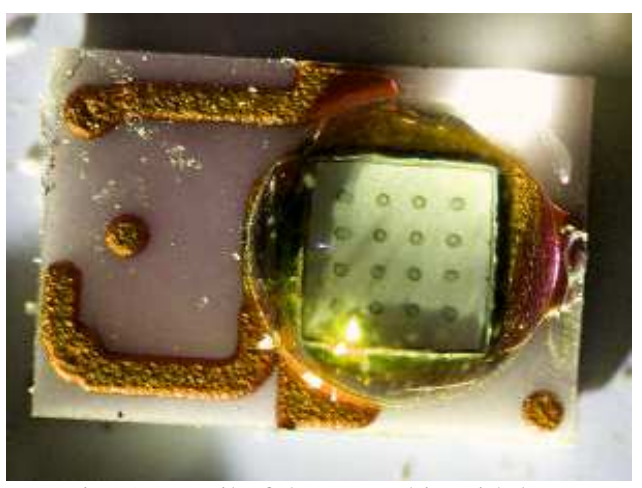

Fig. 5. Detail of the LED chip with lens 


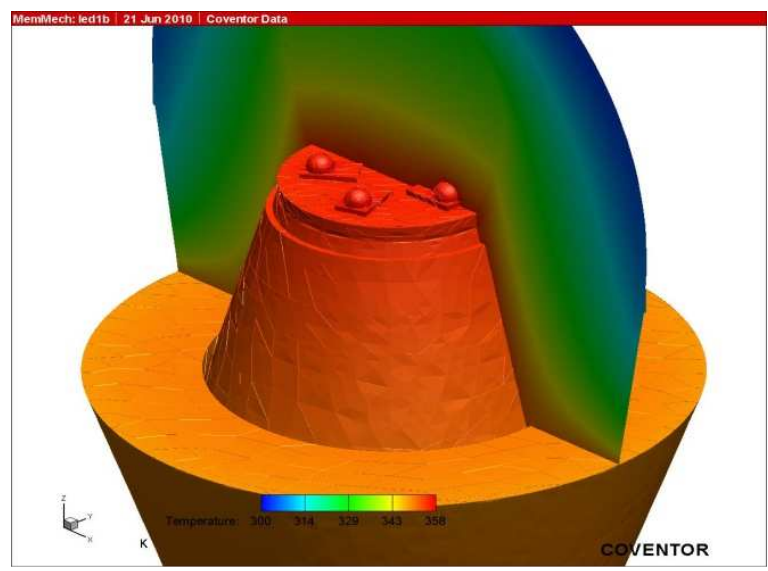

Fig. 6. Temperature distribution in LED lamp when power of $6 \mathrm{~W}$ is applied

\section{Simulation and Measurement Results}

\section{A. Thermal Simulations}

The simulation calculates mechanical displacement of the lamp and value of mechanical strain in the structure when heat is applied [4].

The dissipation power of $4.8 \mathrm{~W}$ and $1.2 \mathrm{~W}$ for heat generation in the six LEDs and the driver respectively were used as input data in CoventorWare thermal analyses The simulation calculates temperature distribution and heat fluxes in the structure and strain arising in connection between different materials due to different coefficient of thermal expansion [4]. Distribution of temperature on surface of LED lamp was validated by IR thermo-imaging and also by contact temperature sensor.

Stresses that are caused by thermal expansion of the used materials are important for the reliability. Therefore a LED board model was designed with most of the LED details, mounting pads, TIM, electrical and thermal vias placed under each LED (Fig. 4).

Transient finite element simulations were performed using CoventorWare to model the thermal rise in time through the LED board and thermal cone to heat sink. The heat flow was assumed to be made by conduction between the heat source (LED chips and driver) and thermal cone and convection from the package to air. In the CoventorWare analysis convection (coefficient of $5 \mathrm{~W} / \mathrm{m}^{2} \mathrm{~K}$ ) and radiation

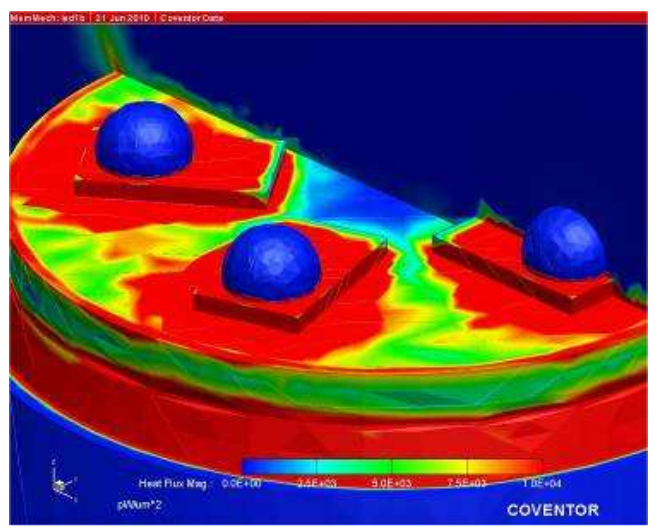

Fig. 8. Heat Flux distribution in detail of board with LEDs

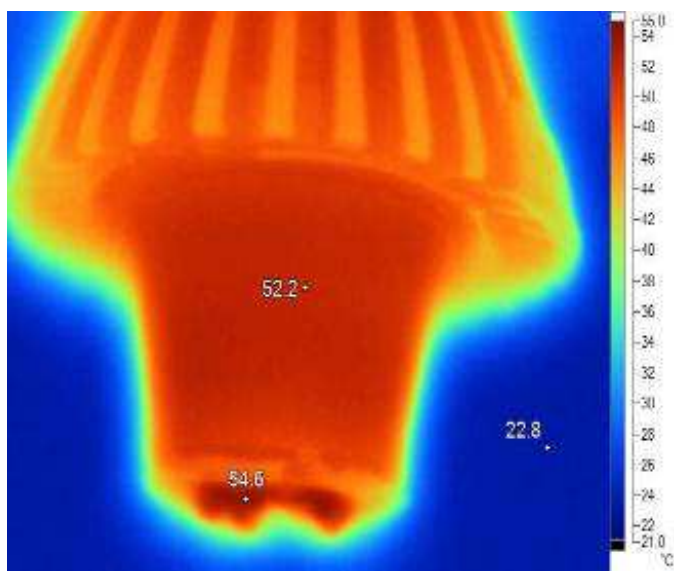

Fig. 7. Thermograph image of the LED lamp with glass cover removed

(emissivity of 1.0 ) to ambient (temperature of $22{ }^{\circ} \mathrm{C}$ ) were prescribed on all inner and outer parts of the lamp which were exposed to air.

The heat flux through the bottom face of the LED board has been taken from the thermal analysis of the LED lamp model. (Fig. 8).

\section{B. Validation with measurement on real lamp}

For validation of the thermal simulations a laboratory test set-up was designed and realized. The test set-up is placed in a room with air ambient temperature of $22^{\circ} \mathrm{C}$. The temperature is measured as a function of time at several fixed point mainly on LED board and heat sink using class A platinum thermometer and infrared thermometer. The glass cover was removable to see the LED board surface temperature by contactless IR thermoimage (Fig. 7). The temperature data were recorded every minute up to $120 \mathrm{~min}$ from switching the cold lamp on.

The experimentally obtained results were compared with the results from the simulation. The rapid increase of the temperature can be seen at the beginning of the test. The steady state conditions were reached after $\sim 90 \mathrm{~min}$ (Fig. 10). The simulation results were in reasonable agreement with the measurement, the deviations are caused by inaccurate material properties (radiation, convection coefficient) that were assumed from literature.

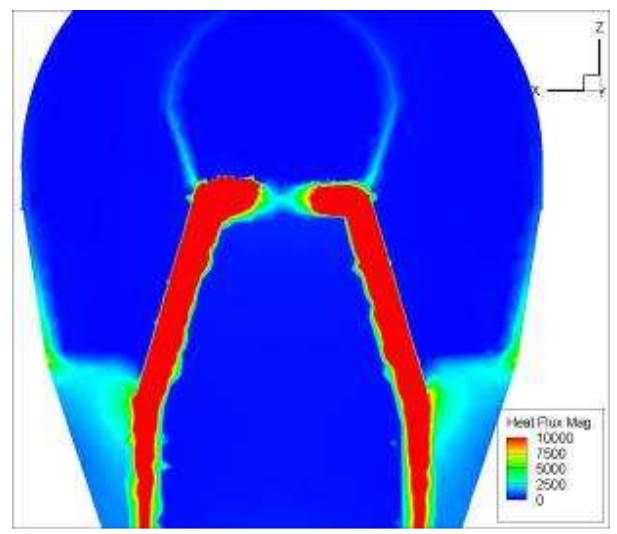

Fig. 9. Heat Flux distribution in aluminum thermal cone 


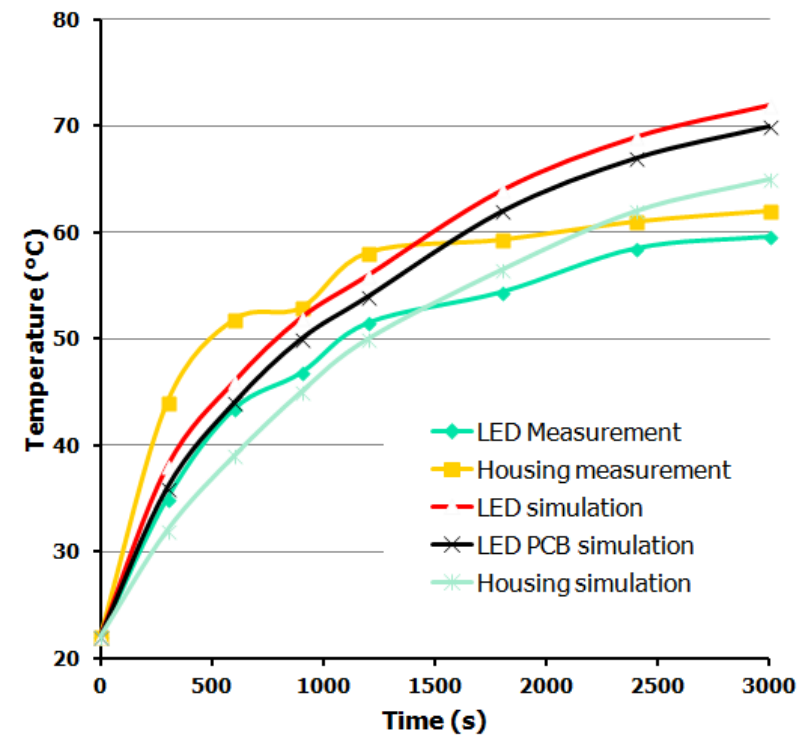

Fig. 10. Heat Flux distribution in aluminum thermal cone (left), Infrared image of real 6W LED lamp

\section{Spectral characteristics}

Wide-band gap compound semiconductors using IIINitrides materials for white light emitting diodes (LEDs) have been subjected to intensive research in recent years. White light for illumination now can be produced from the LEDs either by combination of red, green, and blue emitting chips in one lamp, or by integration of the blue InGaN LED die and the YAG phosphors luminophore into a single package [5]. (this principle is adopted in LED lamp under study). The spectral characteristic exhibits sharp peek at $450 \mathrm{~nm}$ (response from the blue LED) and broad peak from $480 \mathrm{~nm}$ to $730 \mathrm{~nm}$ (response from the phosphoros luminophore).

Comparison of spectral characteristic for LED lamp, incandescent bulb and fluorescent lamp is depicted in Fig. 11. Continuous spectral line (similarly to sun spectra) shows LED lamp and incandescent bulb. Discrete line spectrum with limited number of wavelengths shows fluorescent lamp. This kind of light may be unpleasant for some sensitive people.

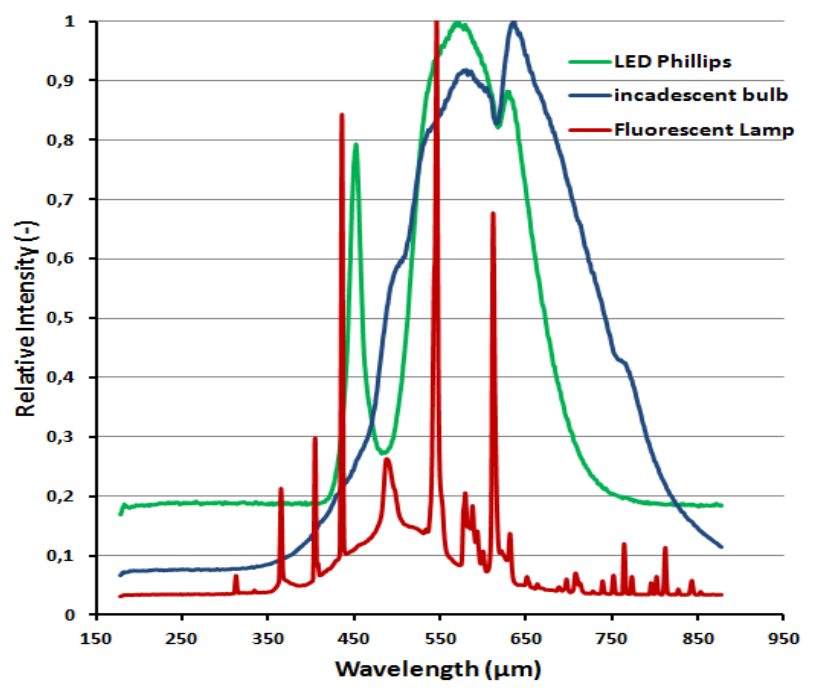

Fig. 11. Spectral characteristic of different light sources

\section{Conclusion}

Themomechanical model of commercially available LED lamp was successfully built and validated with real device. The results of thermal simulation are in reasonable agreement with measurement results performed by both IR imaging and contact temperature measurement. Our results can be interpreted as verification study required for design and simulation of thermal effects and thermal management in complex light sources based of LED.

\section{Acknowledgement}

This work is part of the Consumerizing Solid State Lighting project (CSSL) supported by the ENIAC Joint Undertaking (Grant Agreement No. 120219) and the GAČR project No. 102/09/160.

\section{References}

[1] Poppe A., Lasance J.; On the Standardization of Thermal Characterization of LEDs, LED professional review, Issue 13, ISSN 1993-890X, pp. 22-29, 2009

[2] Jakovenko, J. et al.: Thermal simulation and validation of 8W LED lamp, in proceedings of EuroSim 2011, 2011

[3] Marongiu M.; Thermal Management of High-Power LED Systems, LED Professional review, Issue 13, ISSN 1993890X, pp. 47-50, May-June 2009.

[4] CoventorWare - MemMech reference Manual, 2010

[5] Kim L. et al., " Thermal analysis and design of GaN-based LEDs for high power applications", Physica Status Solidi, pp. 2261-2264, 2003 